\title{
The Importance of Basic and Applied Natural Sciences in Service of Medicine
}

\author{
Hatil Hashim EL-Kamali* \\ Faculty of Science and Technology, Omdurman Islamic University, Sudan
}

Received: January 19, 2018; Published: January 30, 2018

*Corresponding author: Hatil Hashim EL-Kamali, Faculty of Science and Technology, Omdurman Islamic University, Sudan, Email: hatilhashim@gmail.com

\section{Introduction}

The enormous diversity of microorganisms in the environment offers an almost unlimited gene pool for new enzymes and metabolic pathways. The discovery of new natural products continues to be of great interested for the production of pharmaceuticals. An exciting approach to generating new products is to evolve novel metabolic pathways in a microbial cell by means of the technique of metabolic engineering. Cell culture is playing an increasingly more significant role in drug discovery. Animal cell biotechnology constitutes an important field in Biotechnology nowadays. Animal cells produce many biological of great value involving enzymes, hormones, growth factors, viral vaccines, or monoclonal antibodies, and many therapeutic proteins require post-translational modifications which can be only fully performed by animal cells. Insect virus, immune-regulators or whole cells, which are used for toxicological testing, can be obtained from animal.

Plant cells produce a wide range of secondary metabolites, many of which are economically important fine chemicals such as drugs or antioxidants etc... A new approach is expressing microbial genes in plants for producing new compounds, or gives them a new function to metabolize pollutants from the environment. Medicinal chemistry is the application of biology (mainly biochemistry and physiology) and chemistry to the design of new drugs for treating disease, to generate solutions to health related problems. Organic chemistry has been highly disregarded as a discipline of importance for medical and pre-medical curriculums. The impact of biotechnology in the near future will be on the manufacture of biologic gents and reagents that will lead to improved therapy and diagnosis. Various procedures of genetic engineering have caused great importance in the quality of human life, especially in medicine field.
Genetic engineering has had remarkable successes in some areas: basic knowledge about how genes work and recombinant DNA methodology has made available large quantities of substances including insulin, interferon, growth hormones, growth factors, blood-clotting factors and vaccines for diseases such as hepatitis - $\mathrm{B}$, herpes and rabies. Genetic engineering is making it possible to manufacture antibodies, to diagnose and treat diseases, a first step in discovering cures. The used of restriction fragment length polymorphisms (RFLP) and the polymerase chain reaction (PCR) as technique of tremendous power in identifying individuals for forensic purpose (i.e. for DNA fingerprinting). Transgenic mice and cloned sheep have shown that genetic engineering can be applied to higher organisms. AIDS, hemophilia, cystic fibrosis and diabetes are diseases that should be approachable to gene therapy in the near future. Genetic engineering plays an important role in testing and treatment of AIDS. AIDS testing is done by various techniques, such as Western Blots, looking for antibodies to the AIDS proteins. Manipulating stem cells is probably one of the most recognizable forms of genetic engineering in medicine.

In the field of Bioinformatics, the amount of data available through DNA sequencing is shifting research in molecular biology and genetics from a purely experimental approach to one in which experiments can be planned in front of a computer. The analysis of data will allow the identification of genetic markers of diseases and offering clues for therapies including genetic therapy. Trial-anderror experiments can be replaced by predictions that allows for the design of custom-made drugs. Drugs based on rational design they are optimized for the target molecule in question and therefore tend to elicit far fewer side effects, which is a major problem for many therapies. This design is also call for lower doses drugs to achieve the desired effect. 
(C) (i) This work is licensed under Creative

Submission Link: http://biomedres.us/submit-manuscript.php

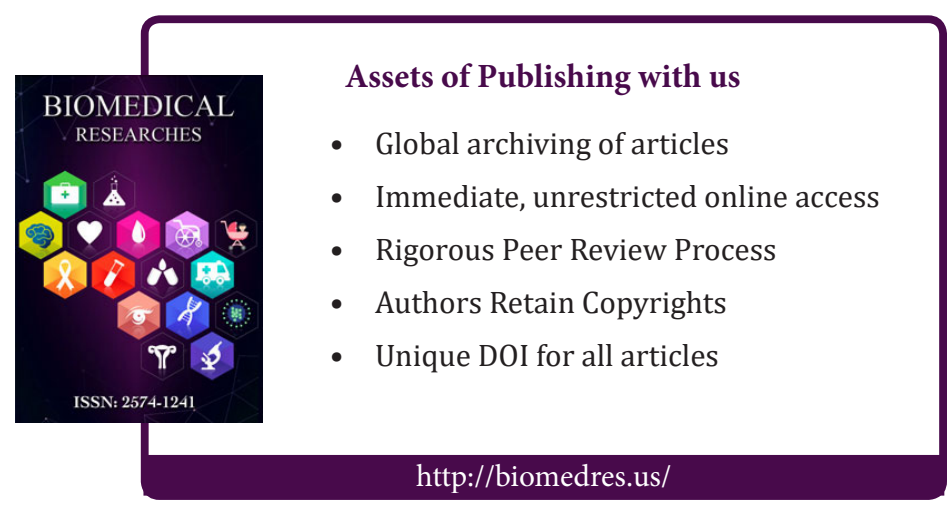

